\title{
Chapter 11 \\ The Modernity of the Meraner Lehrplan for Teaching Geometry Today in Grades 10-11: Exploiting the Power of Dynamic Geometry Systems
}

\section{Maria Flavia Mammana}

\begin{abstract}
In 1905, at the meeting of the Deutschen Mathematiker-Vereinigung in Meran, the "Meraner Lehrplan," a mathematics syllabus, was proposed. This document, which contains many of Felix Klein's ideas on teaching geometry in school, proposed approaching geometry via intuitive geometry, which is the ability to see in space, in order to provide elements for both interpreting the real world and developing logical skills (see Treutlein in Der geometrische anschauungsunterricht als unterstufe eines zweistufigen geometrischen unterrichtes an unseren höheren schulen. Teubner, Leipzig/Berlin 1911). Klein's ideas still hold today: An intuitive approach to geometry can be facilitated using information technology. Some activities related to a space geometry approach based on the analogy among figures and on the use of a dynamic geometry system will be presented in this chapter.
\end{abstract}

Keywords Teaching/learning geometry $\cdot$ Dynamic geometry system Quadrilaterals · Tetrahedra

\subsection{Introduction}

At the beginning of the 20th century, teaching and pedagogical experience suggested the opportunity to consider — at the school level—intuitive geometry as a preliminary to Euclidean geometry. Proposals for intuitive handling of geometry came from a variety of countries. Felix Klein was one of the major proponents of these ideas.

Klein's ideas were well represented by the curriculum proposed in 1905 by a special commission at a meeting of scientists in Meran (part of Austria at that time) and then republished by Klein and Schimmak (1907). This document, the Meraner Lehrplan, proposed that geometrical teaching begins with the observation of objects of everyday life:

\footnotetext{
M. F. Mammana ( $\square)$

Department of Mathematics and Computer Science, University of Catania, Catania, Italy e-mail: fmammana@dmi.unict.it
} 
Preliminary geometry: Introduction to fundamental ideas of space as it may be observed, in such a way, however, that space appears chiefly as involving plane properties. Dimensions, surface lines, points, explained first in relation to immediate objects and illustrated from widely different bodies. Plane figures as part of the boundaries of bodies, then as independent forms in which the idea of direction, angle, parallelism, symmetry are to be brought out.... (Price 1911, p. 179)

It continues with the study of basic concepts of figures, lines, triangles, and parallelograms and then trapeziums and circles: "Properties of straight lines, angles and triangles; variation of figures in shape and size; ... simple properties of parallelogram deduced from the construction of figures. Extension of the parallelogram properties. The trapezium. Fundamental properties of the circle..." (Price 1911, p. 179). It then follows the theoretical study of the properties of figures, for students of 13-17 years, and the study of solid geometry, including exercises in drawing.

In textbooks that followed this proposal, intuitive geometry is seen as the ability to see into space and will provide items both to interpret the real world and to develop logical skills (Menghini 2010). Illustrating the work of various authors, Fujita et al. (2004) define intuitive geometry as "a skill to see geometrical figures and solids, creating and manipulating them in the mind to solve problems in geometry"' (p. 2).

Klein's ideas still hold today: An intuitive approach to geometry can be facilitated by the use of information technology. Some activities related to the space geometry approach that are based on both the analogy among figures and on the use of dynamic geometry software are presented here.

\subsection{Teaching Space Geometry in School}

Space geometry is part of school curricula but in classrooms it is often relegated to the end of the year and therefore covered superficially at best, if not left out completely. In fact, even though we live in a three-dimensional space, teaching/learning three-dimensional geometry presents difficulties in graphic representation and mental visualization: It is not easy to draw a three-dimensional figure on a plane and it is not easy to imagine the mutual positions of objects in space.

A new and catchy approach to three-dimensional geometry has been realized by means of analogy. Analogy is a "sort of similarity among distinct objects. Similar objects agree with each other in some aspect, analogous objects agree in clearly definable relations of their respective parts" (Polya 1957, p. 37). A problem can be solved using the solution of an analogous simpler problem: Use its method, result, or both. In our case, an analogy between quadrilaterals and tetrahedra can be found. In what follows, both results and method that were used to study some properties of quadrilaterals are then traced step by step in facing analogous properties of tetrahedra. The use of this analogy turns out to be very useful because it represents a bridge that creates a significant link between two and three dimensions (Mammana et al. 2012).

The use of dynamic geometry software (DGS) can also help: Cabri Géomètre (Geogebra can also be used) allows us to not only easily build plane and space geo- 
metric figures but also to dynamically change them without modifying the properties used in building them. In particular, Cabri 3D, the three-dimensional version of Cabri Géomètre, can be a really useful instrument to overcome problems inherent in the visualization of three-dimensional figures.

The use of a DGS is not, of course, a panacea for all problems in teaching and learning geometry. Moreover, using DGS does not mean that you prove a geometrical problem, but only see that a property might be true. But I agree with Hofstadter's words, related to the use of Geometer's Sketchpad:

The beauty of Geometer's Sketchpad is that it allows you to discover instantly whether a conjecture is right or wrong-if it's wrong, it will be immediately obvious when you play around with a construction dynamically on the screen. If it's right, things will "stay in synch" right on the button no matter how you play with the figure. The degree of certainty and confidence that this gives is downright amazing. It's not a proof, of course, but in some sense, I would argue, this kind of direct contact with the phenomenon is even more convincing than a proof, because you really see it all happening right there before your eyes.... I just am not one who believes that certainty can come only from proofs. (Hofstadter 1997, p. 10)

\subsection{The Content of the Activity}

The content of the activity refers to a paper by Mammana et al. (2009). This paper shows the existence of a surprising analogy between quadrilaterals and tetrahedra, determining some properties that hold for both families of figures. In the following, only some definitions and properties that highlight the existing analogy between the quadrilaterals and tetrahedra are reported.

A quadrilateral $\boldsymbol{Q}$ is determined by four coplanar points, A, B, C, and D, called vertices, such that any three of them are non-collinear. The vertices determine six segments, AB, BC, CD, DA, AC, and BD, called edges. There are six edges: four sides and two diagonals. We call faces of $\boldsymbol{Q}$ the triangles determined by three vertices of $\boldsymbol{Q}$. Then there are four faces: ABC, BCD, CDA, and DAB (Fig. 11.1). In a similar manner, a tetrahedron $\boldsymbol{T}$ is determined by four non-coplanar points, A, B, C, and $\mathrm{D}$, called vertices. The vertices determine six segments, AB, BC, CD, DA, AC, and BD, called edges. We call faces of $\boldsymbol{T}$ the triangles determined by three vertices of $\boldsymbol{T}$. There are four faces: ABC, BCD, CDA, and DAB (Fig. 11.1).

From now on we will assume that $\boldsymbol{F}$ is a quadrilateral or a tetrahedron of vertices $\mathrm{A}, \mathrm{B}, \mathrm{C}$, and D.

Two edges of $\boldsymbol{F}$ are said to be opposite if they do not have common vertices. AB and $\mathrm{CD}, \mathrm{BC}$ and $\mathrm{DA}$, and $\mathrm{AC}$ and $\mathrm{BD}$ are then opposite edges. A vertex and a face of $\boldsymbol{F}$ are said to be opposite if the vertex does not belong to the face. For each vertex there is one and only one opposite face. For example, BCD is the opposite face to the vertex $A$.

A bimedian of $\boldsymbol{F}$ is the segment joining the midpoints of two opposite edges. Let $\mathrm{M}_{1}, \mathrm{M}_{2}, \mathrm{M}_{3}, \mathrm{M}_{4}, \mathrm{M}_{5}$, and $\mathrm{M}_{6}$ be the midpoints of the edges AB, BC, CD, DA, AC, and BD, respectively. Then $\boldsymbol{F}$ has three bimedians: $\mathrm{M}_{1} \mathrm{M}_{3}, \mathrm{M}_{2} \mathrm{M}_{4}$, and $\mathrm{M}_{5} \mathrm{M}_{6}$. 


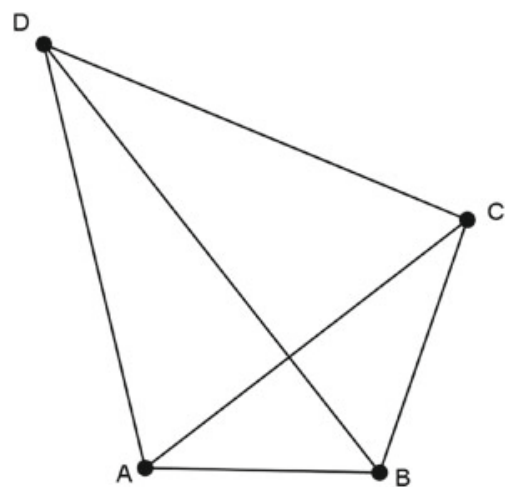

Fig. 11.1 Quadrilateral or tetrahedron

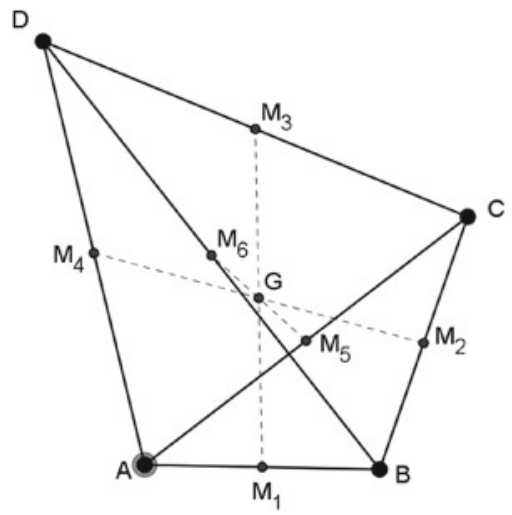

Fig. 11.2 Bimedians and centroid

Theorem 1 The three bimedians of a quadrilateral or of a tetrahedron all pass through one point which bisects each bimedian.

The point $\mathrm{G}$ common to the three bimedians of $\boldsymbol{F}$ is called the centroid of $\boldsymbol{F}$ (Fig. 11.2).

A median of $\boldsymbol{F}$ is the segment joining a vertex with the centroid of the opposite face (being the centroid of the opposite face the centroid of the triangle opposite to the vertex). Let $\mathrm{A}^{\prime}, \mathrm{B}^{\prime}, \mathrm{C}^{\prime}$, and $\mathrm{D}^{\prime}$ be the centroids of the faces opposite to the vertices $\mathrm{A}, \mathrm{B}, \mathrm{C}$, and D, respectively. Then $\mathrm{F}$ has four medians: $\mathrm{AA}^{\prime}, \mathrm{BB}^{\prime}, \mathrm{CC}^{\prime}$, and $\mathrm{DD}^{\prime}$.

Theorem 2 The four medians of a quadrilateral or a tetrahedron $\boldsymbol{F}$ meet in its centroid, which divides each median in the ratio 1:3, the longer segment being on the side of the vertex of $\boldsymbol{F}$ (Commandino's theorem; see Fig. 11.3).

A maltitude of a quadrilateral $\boldsymbol{F}$, relative to an edge, is the line of the plane containing $\boldsymbol{F}$ that is perpendicular to the edge and passes through the midpoint of the opposite edge. Then $\boldsymbol{F}$ has six maltitudes. 


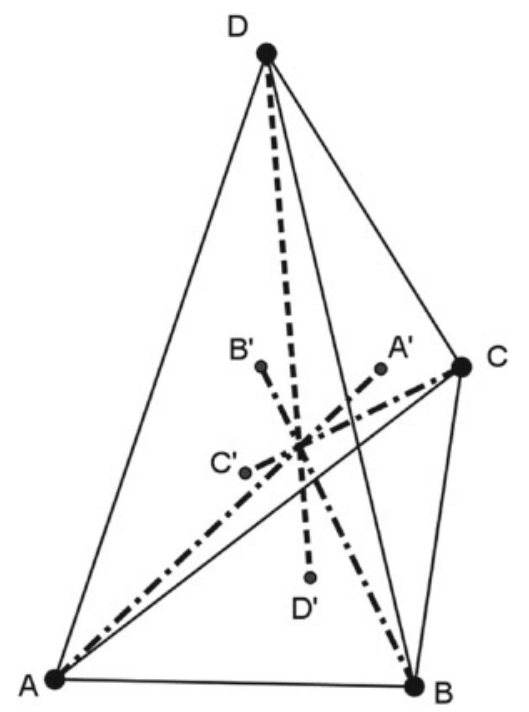

Fig. 11.3 Medians

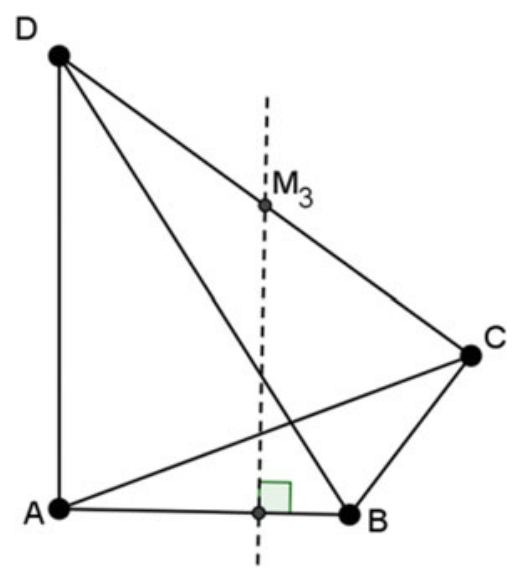

Fig. 11.4 Maltitude

The Monge plane of a tetrahedron $\boldsymbol{F}$, relative to an edge, is the plane perpendicular to the edge passing through the midpoint of the opposite edge. Then $\boldsymbol{F}$ has six Monge planes.

Theorem 3 The maltitudes of a cyclic quadrilateral are concurrent. The Monge planes of a tetrahedron are concurrent (see Fig. 11.4).

The analogy of the definitions and properties is summarized in the following table. 


\begin{tabular}{|c|c|}
\hline Quadrilaterals & Tetrahedra \\
\hline $\begin{array}{l}\boldsymbol{Q} \text { is a convex quadrilateral with vertices A, B, } \\
\text { C, D } \\
\text { The points A, B, C, D are such that any three } \\
\text { of them are non-collinear } \\
\text { The vertices detect six segments AB, BC, CD, } \\
\text { DA, AC, BD that are called edges. The edges } \\
\text { of } \boldsymbol{Q} \text { are the four sides and the two diagonals } \\
\text { Two edges are said to be opposite if they do not } \\
\text { have common vertices } \\
\text { We call faces of } \boldsymbol{Q} \text { the triangles determined by } \\
\text { three vertices of } \boldsymbol{Q} \\
\text { A vertex and a face are said to be opposite if } \\
\text { the vertex does not belong to the face. For each } \\
\text { vertex there is one and only one opposite face }\end{array}$ & $\begin{array}{l}\boldsymbol{T} \text { is a tetrahedron with vertices A, B, C, D } \\
\text { The points A, B, C, D are non-coplanar } \\
\text { The vertices detect six segments AB, BC, CD, } \\
\text { DA, AC, BD that are called edges } \\
\text { Two edges are said to be opposite if they do not } \\
\text { have common vertices } \\
\text { We call faces of } \boldsymbol{T} \text { the triangles determined by } \\
\text { three vertices of } \boldsymbol{T} \\
\text { A vertex and a face are said to be opposite if } \\
\text { the vertex does not belong to the face. For each } \\
\text { vertex there is one and only one opposite face }\end{array}$ \\
\hline $\begin{array}{l}\text { The segment joining the midpoints of two } \\
\text { opposite edges of } \boldsymbol{Q} \text { is called bimedian of } \boldsymbol{Q} \\
Q \text { has three bimedians, two relative to a pair of } \\
\text { opposite sides and one relative to the diagonals } \\
\text { Theorem } 1 . \text { The three bimedians of a } \\
\text { quadrilateral all pass through one point which } \\
\text { bisects each bimedian } \\
\text { The point G common to the three bimedians of } \\
\boldsymbol{Q} \text { is called centroid of } \boldsymbol{Q}\end{array}$ & $\begin{array}{l}\text { The segment joining the midpoints of two } \\
\text { opposite edges of } T \text { is called bimedian of } \boldsymbol{T} . \boldsymbol{T} \\
\text { has three bimedians } \\
\text { Theorem 1. The three bimedians of a } \\
\text { tetrahedron all pass through one point which } \\
\text { bisects each bimedian } \\
\text { The point G common to the three bimedians of } \\
\boldsymbol{T} \text { is called centroid of } \boldsymbol{T}\end{array}$ \\
\hline $\begin{array}{l}\text { The segment joining a vertex of } \boldsymbol{Q} \text { with the } \\
\text { centroid of the opposite face is called median } \\
\text { of } \boldsymbol{Q} \cdot \boldsymbol{Q} \text { has four medians } \\
\text { Theorem 2. The four medians of a } \\
\text { quadrilateral meet in its centroid, which } \\
\text { divides each median in the ratio } 1: 3 \text {, the longer } \\
\text { segment being on the side of the vertex of } \mathbf{Q}\end{array}$ & $\begin{array}{l}\text { The segment joining a vertex of } \boldsymbol{T} \text { with the } \\
\text { centroid of the opposite face is called median } \\
\text { of } \boldsymbol{T} . \boldsymbol{T} \text { has four medians } \\
\text { Theorem 2. The four medians of a tetrahedron } \\
\text { meet in its centroid, which divides each median } \\
\text { in the ratio 1:3, the longer segment being on } \\
\text { the side of the vertex of } \mathbf{T} \text {. (Commandino's } \\
\text { Theorem) }\end{array}$ \\
\hline $\begin{array}{l}\text { The line that is perpendicular to an edge of a } \\
\text { quadrilateral } \boldsymbol{Q} \text { and passes through the } \\
\text { midpoint of the opposite edge is called } \\
\text { maltitude of } \boldsymbol{Q} \cdot \boldsymbol{Q} \text { has six maltitudes } \\
\text { Theorem 7. The maltitudes of a cyclic } \\
\text { quadrilateral are concurrent } \\
\text { The common point to the six maltitudes of a } \\
\text { cyclic quadrilateral } \boldsymbol{Q} \text { is called anticenter of } \boldsymbol{Q}\end{array}$ & $\begin{array}{l}\text { The plane that is perpendicular to an edge of a } \\
\text { tetrahedron } \boldsymbol{T} \text { and passes through the midpoint } \\
\text { of the opposite edge is called Monge plane of } \\
\boldsymbol{T} . \boldsymbol{T} \text { has six Monge planes } \\
\text { Theorem 7. The Monge planes of a tetrahedron } \\
\text { are concurrent. (Monge Theorem) } \\
\text { The common point to the six Monge planes of } \\
\text { a tetrahedron } \boldsymbol{T} \text { is called Monge point of } \boldsymbol{T}\end{array}$ \\
\hline
\end{tabular}

The statements and the proofs of the theorems are the same for both families of figures. The propositions presented are simple and easy to prove, so they can be easily used by teachers. The analogy between known plane figures, quadrilaterals, and figures that students do not usually study much, tetrahedra, allows the teacher to develop a stimulating activity in three-dimensional geometry. The analogy between quadrilaterals and tetrahedra offers an opportunity to develop geometry in two and three dimensions in parallel (Mammana et al. 2009). 


\subsection{Activities}

The results contained in Mammana et al. (2009) have been successfully used in several activities that have been carried out in the first two years of high school, promoting an introduction of three-dimensional geometry and visualization (Mammana and Pennisi 2010; Mammana et al. 2012; Ferrara and Mammana 2013, 2014). The educational rationale of the activities was to have students experience 3D geometry in order to enhance their sense of self-efficacy, help them reach an accurate vision of the discipline, and experience positive emotional stimulation by fostering the students' positive attitude towards space geometry.

Usually, the activity starts by studying quadrilaterals, already familiar to the students, and then it continues by studying tetrahedra, using the numerous analogies with quadrilaterals. Thus, space geometry is less difficult because students are faced with 3D problems after having already become familiar with the solution of an analogous problem in the plane. The teaching/learning strategy that was used followed the scheme:

- Explore and verify using Cabri

- Conjecture

- Prove

This is done, for example, by observing and exploring a figure, perceiving the relations between objects, manipulating the figure, and experimentally verifying the hypothesis. Once the hypotheses are confirmed, a conjecture is formulated and finally proved.

During the whole activity, students usually work in pairs and on two computers: One computer is used to work on plane figures, the other to work on space figures. The whole activity is supported by worksheets that have been designed for this purpose: For each 2D worksheet there is a 3D worksheet. In this way there is an immediate correlation between the plane figures and space figures involved in the study. An example of a worksheet can be found in Mammana and Pennisi (2010).

The passage from plane to space is done by means of a specific Cabri 3D tool, the "redefinition" tool. This is the key to the activity that, from a teaching point of view, makes the analogy work.

In Cabri 3D, given a quadrilateral with its diagonals (Fig. 11.5a), it is possible to use the redefinition tool to redefine a point, for example $\mathrm{D}$ out of the plane of $\mathrm{ABC}$ (Fig. 11.5b). In this way, the quadrilateral becomes a tetrahedron, the vertices of the quadrilateral become the vertices of the tetrahedron, and the edges of the quadrilateral become the edges of the tetrahedron.

With the redefinition tool we can move from plane to space when investigating for bimedians (Fig. 11.6a, b) and medians (Fig. 11.7a, b). Once the tetrahedron is built it is possible to see it from all sides by activating the "glass ball" function. This action allows the students to change their point of view in order to see the figure from different perspectives.

The whole activity can be carried out in a mathematics laboratory: 

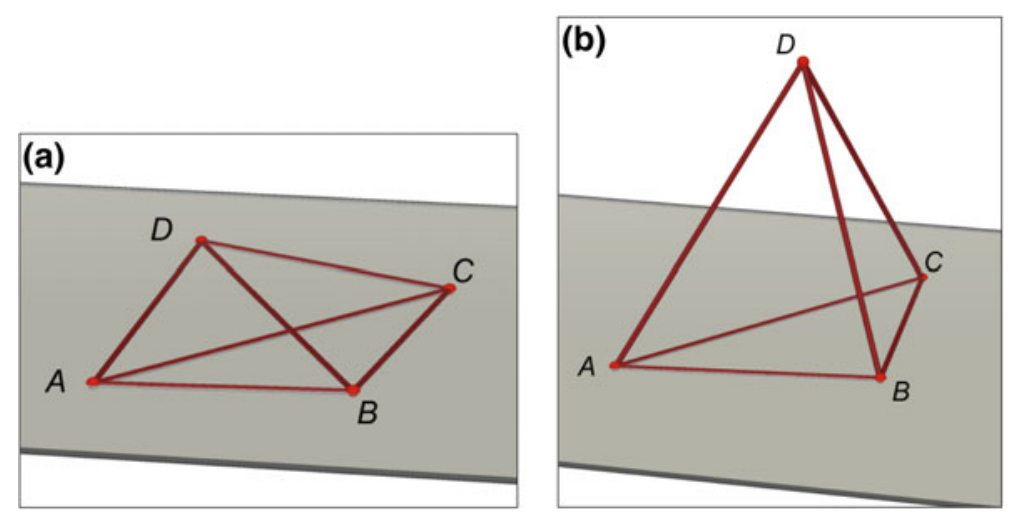

Fig. 11.5 a Quadrilateral. b Tetrahedron
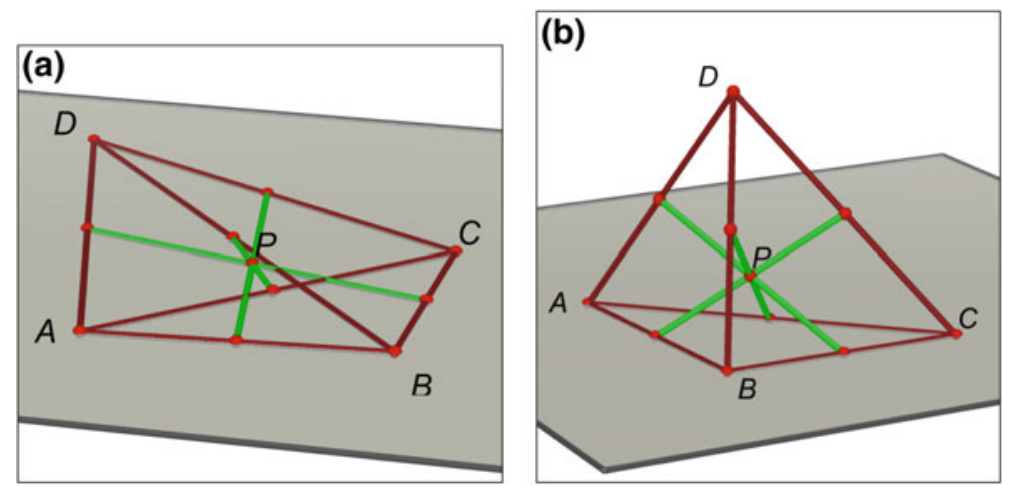

Fig. 11.6 a Bimedians of a quadrilateral. b Bimedians of a tetrahedron

We can imagine the laboratory environment as a Renaissance workshop in which the apprentices learned by doing, seeing, imitating, and communicating with each other, in a word: practicing. In the laboratory activities, the construction of meanings is strictly bound, on one hand, to the use of tools, and on the other, to the interactions between people working together ... [and] to the communication and sharing of knowledge in the classroom, either working in small groups in a collaborative and cooperative way, or by using the methodological instrument of the mathematic discussion, conveniently lead by the teacher. (Anichini et al. 2004; own translation).

A math teaching laboratory, then, is intended as

a phenomenological space to teach and learn mathematics developed by means of specific technological tools and structured negotiation processes in which math knowledge is subjected to a new representative, operative, and social order to again become the object of investigation and be efficaciously taught and learnt. (Chiappini 2007; own translation)

The mathematics laboratory is not just the use of a computer (or two computers, since the students work in pairs). Rather, it is an activity for the classroom that has 

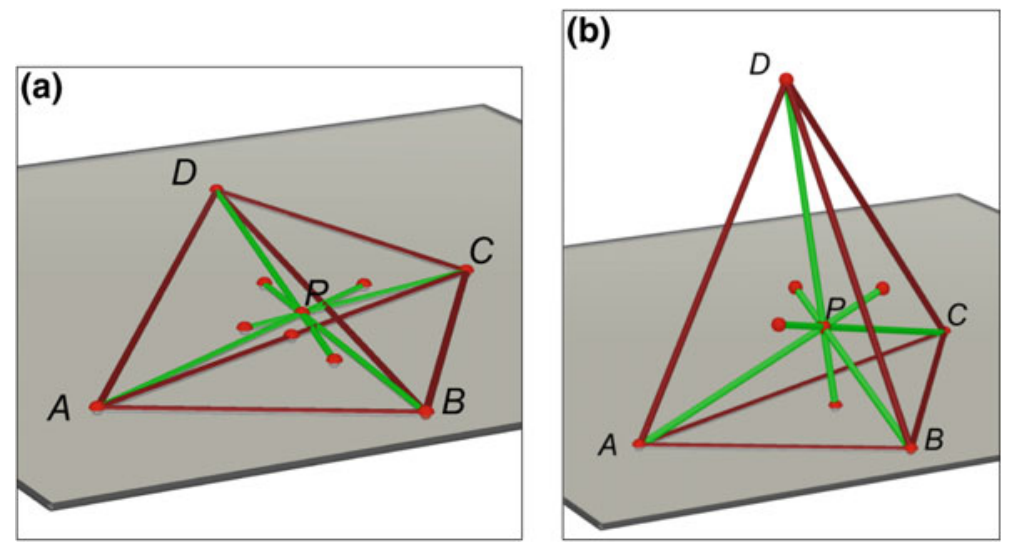

Fig. 11.7 a Medians of a quadrilateral. b Medians of a tetrahedron

been deeply thought through and structured by the teacher. The teacher, together with the students, the topic, and the structured activity are the main actors of the mathematics laboratory.

\subsection{Conclusions}

In an activity like the one that is proposed here, the following are crucial:

- The analogy between figures, an analogy that holds both in properties and in proofs, in the sense of the Meraner plan: "Geometry. Similarity, with special stress on similar situation."

- The use of technology that helps in drawing the figure, in discovering properties (with the dragging mode or the redefinition tool), and in seeing the figure (with the glass ball), in the sense of the Meraner plan: "Ideas of space as it may be observed."

Among teachers and students, spatial geometry has a general reputation for being difficult because it is difficult to see. Seeing in 3D geometry is, especially at a school level, very important. Euclidean geometry also allows us to interpret the space we live in: Seeing mathematics in everyday life is very crucial. We need to adjust our eye to what we have right in front of us. For example, as recently as June 2012, a 17-year-old student taking pictures during an excursion with her classmates near Syracuse in Sicily noted that there was a face in the rock she was taking a picture of (Fig. 11.8): "A simple click can bring out prodigious things that sometimes may escape the naked eye" (Ferrara and Mammana 2013).

So, I ask you, reader, what do you see in the famous Kandinsky painting Squares with Concentric Circles (Fig. 11.9)? 


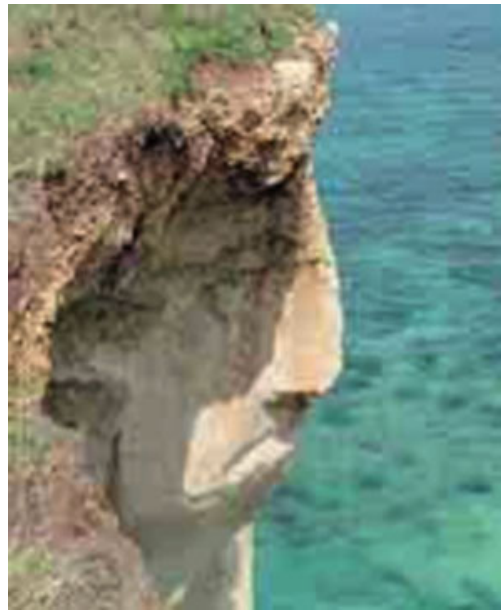

Fig. 11.8 Face in the rock

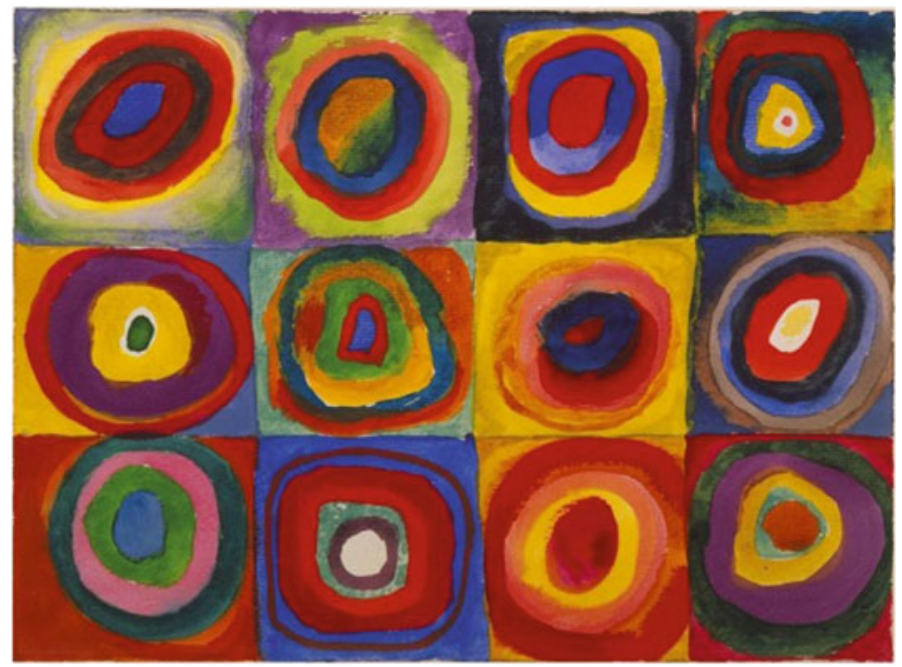

Fig. 11.9 Squares with concentric circles

Maria Roberta, a seven-year-old second grader saw in the Kandinsky painting an axial symmetry (Fig. 11.10) and, even more, multiples of four (Fig. 11.11) and multiples of three (Fig. 11.12).

Maria Roberta, in her homework assignment on finding 3D geometrical objects in the kitchen, brought to school a salt container (a cylinder), sugar crystals (a sphere), a Toblerone box (a prism), and she carried everything in doll luggage (a parallelepiped).

The geometry activity presented here helps students approach 3D geometry: It involves manipulative activities (with digital technologies) in order to get an intuitive 


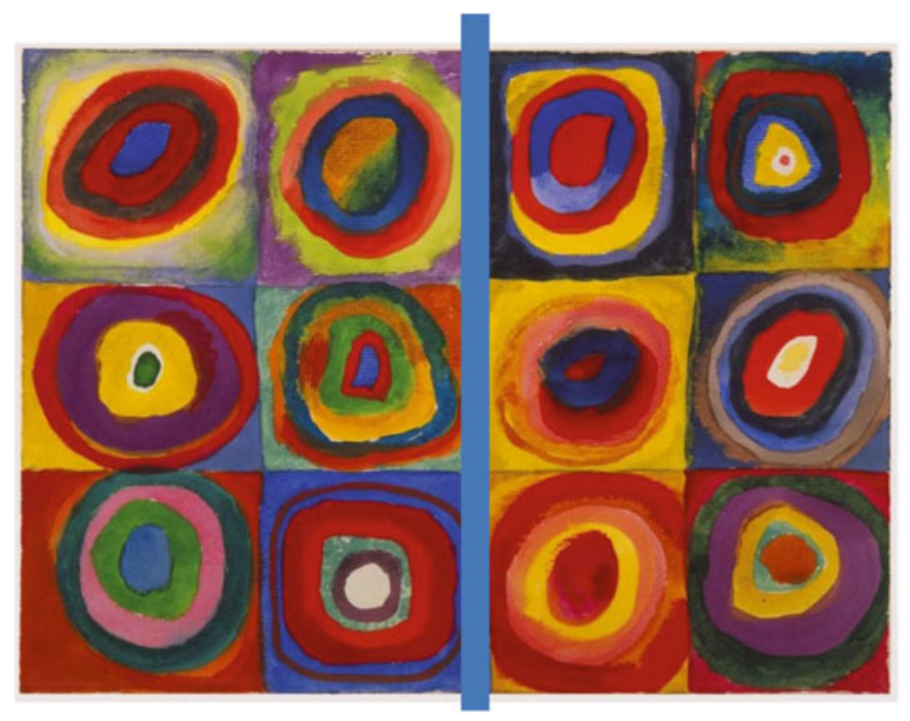

Fig. 11.10 Axial symmetry

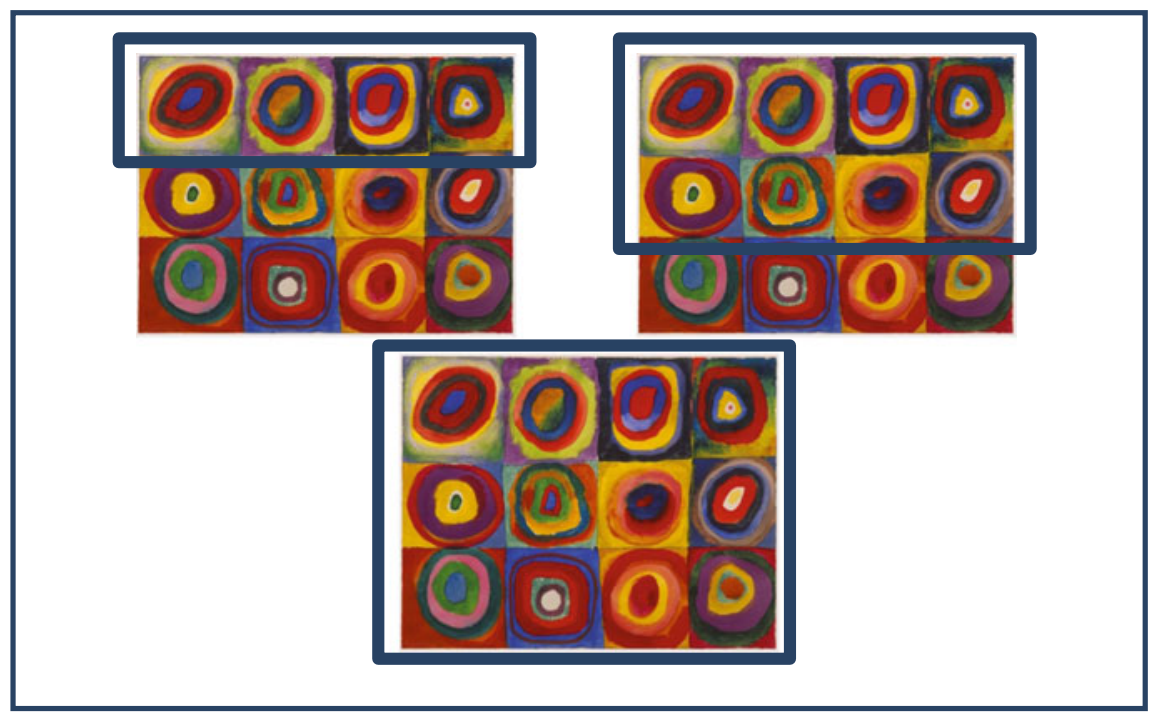

Fig. 11.11 Multiples of four

knowledge of the properties that will be then formalized. The whole process relies on "similarity, with special stress on similar situation" (Klein and Schimmak 1907) and developing the attitudes of "seeing objects." Training the eye to explore can be done not only in a dynamic geometry environment, but also at an early stage by 

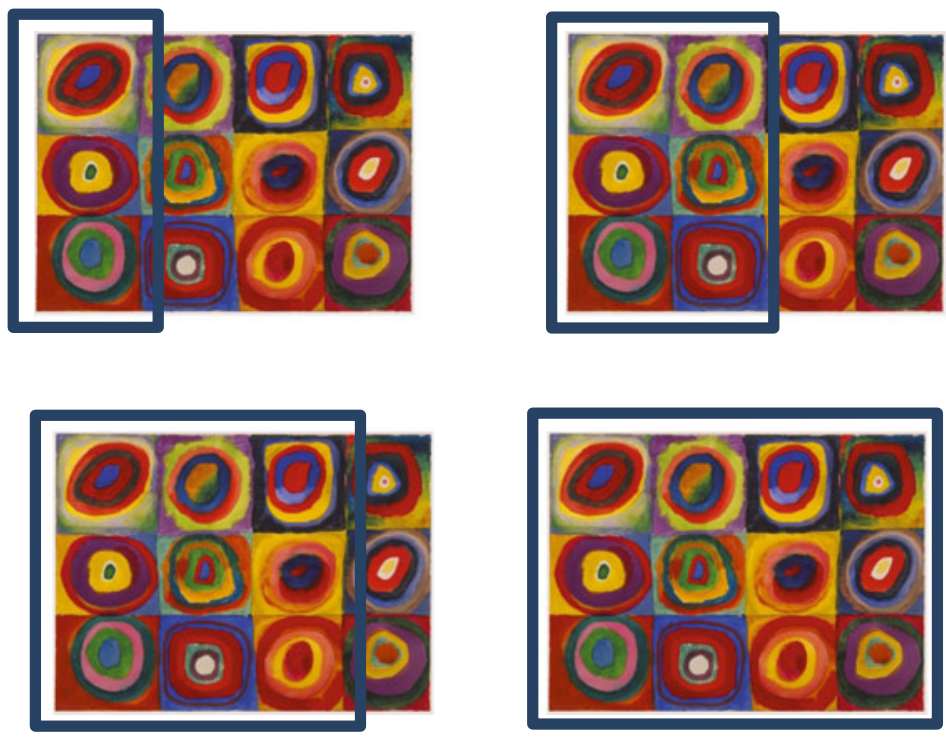

Fig. 11.12 Multiples of three

observing carefully what surrounds us (see Maria Roberta's activities that took her to see mathematics even in a painting!).

Let's help our students to see!

\section{References}

Anichini, G., Arzarello, F., Ciarrapico, L., et al. (Eds.). (2004). Matematica 2003. (Mathematics 2003). Lucca: Matteoni stampatore.

Chiappini, G. (2007). Il laboratorio didattico di matematica: Riferimenti teorici per la sua costruzione. [The didactical laboratory of mathematics: Theoretical references about its construction]. Innovazione educativa, 8, 9-12.

Ferrara, F., \& Mammana, M. (2013). Close your eyes and see ... An approach to spatial geometry. In B. Ubuz, Ç. Haser, \& M. A. Mariotti (Eds.), Proceedings of the Eighteenth Congress of the European Society for Research in Mathematics Education (pp. 625-634). Antalya (Turkey): Middle East Technical University.

Ferrara, F., \& Mammana, M. (2014). Seeing in space is difficult: An approach to 3D geometry through a DGE. In P. Liljedahl, C. Nicol, S. Oesterle, \& D. Allan (Eds.), Proceedings of the Joint Meeting of PME 38 and PME-NA 36 (Vol. 3, pp. 57-64). Vancouver, Canada: PME.

Fujita, T., Jones, K., \& Yamamoto, S. (2004). The role of intuition in geometry education: Learning from the teaching practice in the early 20th century. Paper presented to Topic Study Group 29 
(TSG29) at the 10th International Congress on Mathematical Education. Copenhagen, Denmark, July 4-11, 2004.

Hofstadter, D. R. (1997). Discovery and dissection of a geometric gem. In J. King \& D. Schattschneider (Eds.), Geometry turned on! Dynamic software in learning, teaching, and research. Washington (pp. 3-14). Washington, D.C.: The Mathematical Association of America.

Klein, F., \& Schimmak, R. (1907). Der Meraner Lehrplan für Mathematik. In F. Klein (Ed.), Vorträge über den mathematischen Unterricht an den höheren Schulen. Bearbeitet von Rudolf Schimmack. Teil 1: Von der Organisation des mathematischen Unterrichts (pp. 208-220). Leipzig: Teubner.

Mammana, M., Micale, B., \& Pennisi, M. (2009). Quadrilaterals and tetrahedra. International Journal of Mathematical Education in Science and Technology, 40(6), 817-828.

Mammana, M., Micale, B., \& Pennisi, M. (2012). Analogy and dynamic geometry system used to introduce three-dimensional geometry. International Journal of Mathematical Education in Science and Technology, 43(6), 818-830.

Mammana, M., \& Pennisi, M. (2010). Dragging quadrilaterals into tetrahedra. In W.-C. Yang, M. Majewski, T. de Alwis, \& W. P. Hew (Eds.), Proceedings of the 15th Asian Technology Conference in Mathematics (pp. 373-384). Blacksburg, VA: Mathematics and Technology.

Menghini, M. (2010). La geometria intuitiva nella scuola media italiana del '900. [Intuitive geometry in the Italian middle school at 1900]. La Matematica nella Società e nella Cultura. Rivista dell'Unione Matematica Italiana, I(III), 399-429.

Polya, G. (1957). How to solve it. Princeton, NJ: Princeton University Press.

Price, E. (1911). The "Meraner Lehrplan." mathematical curriculum for gymnasia. The Mathematical Gazette, 6(95), 179-181.

Treutlein, P. (1911). Der geometrische anschauungsunterricht als unterstufe eines zweistufigen geometrischen unterrichtes an unseren höheren schulen. Leipzig/Berlin: Teubner. 
Open Access This chapter is licensed under the terms of the Creative Commons Attribution 4.0 International License (http://creativecommons.org/licenses/by/4.0/), which permits use, sharing, adaptation, distribution and reproduction in any medium or format, as long as you give appropriate credit to the original author(s) and the source, provide a link to the Creative Commons license and indicate if changes were made.

The images or other third party material in this chapter are included in the chapter's Creative Commons license, unless indicated otherwise in a credit line to the material. If material is not included in the chapter's Creative Commons license and your intended use is not permitted by statutory regulation or exceeds the permitted use, you will need to obtain permission directly from the copyright holder.

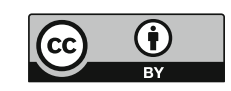

